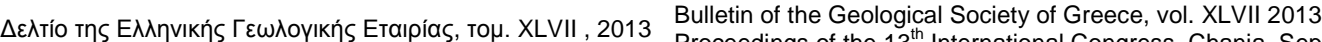

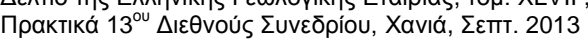
2013

\title{
SÃO PAULO CAVERN-SHAFT COLLAPSE VIEWED AS A TRAP-DOOR PROBLEM
}

\author{
Saratsis G. ${ }^{1}$ and Stavropoulou M. ${ }^{2}$ \\ ${ }^{1}$ Mine Design Lab, Mineral Resources Engineering Department, Technical University of Crete \\ (gsaratsi@gmail.com) \\ ${ }^{2}$ National and Kapodistrian University of Athens, Faculty of Geology and Geoenvironment, \\ Department of Dynamic, Tectonic and Applied Geology, , GR-15784, Greece \\ (mstavrop@geol.uoa.gr)
}

\begin{abstract}
This paper refers to the numerical simulation of the conditions that have lead to the collapse of the shaft-cavern collapse in São Paulo, Brazil (2007) constructed with the Conventional Tunnelling Method (CTM) or the New Austrian Tunneling Technique (NATM). The Pinheiros station where the incident has occurred, is located in an area known as the Caucaia Shear Zone, resulting in a highly fractured medium (four main families of discontinuities, i.e. two subvertical and two dipping towards the tunnel walls).The main observed lithologies were biotite gneiss and granite gneiss. According to the Bieniawski classification, the following rock mass classes were observed: II,III,IV (partially corresponding to saprolite), and V (partially corresponding to residual soils). The shaft-tunnel construction is simulated by virtue of the $3 D$ finite differences code FLAC $3 D^{\mathrm{TM}}$. Special emphasis is given on the appropriate quantitative description of the geological conditions. A kinematic cohesion-friction softening model of the discontinuous rock mass is used. It was found that failure is manifested with the evolution of shear bands starting from the corners of the cavern periphery as this approaches the shaft while retreating. Before this, another cylindrical shear band initiates from the bottom of the shaft and also propagates upwards to connect with the former and hence producing the final collapse.
\end{abstract}

Key words: shear band, strain softening, strain localization, jointed rock.

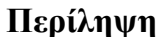

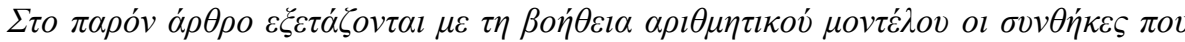

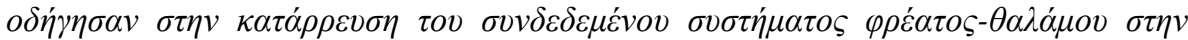

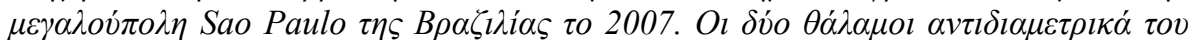

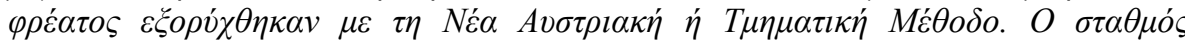

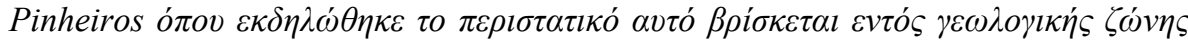

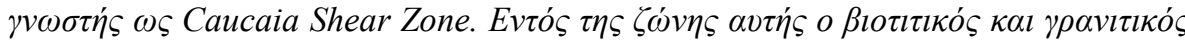

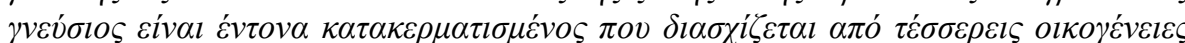

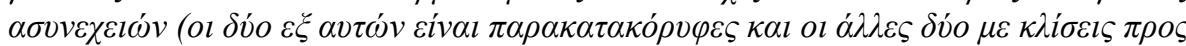

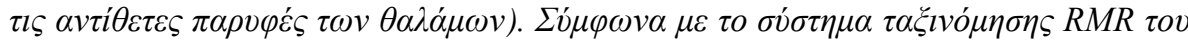

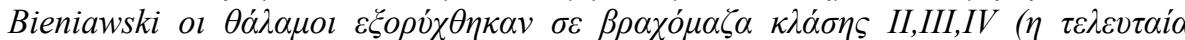

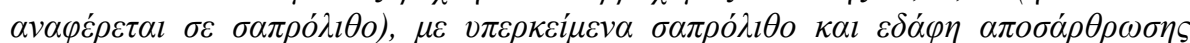

$\underline{\text { XLVII, No } 3-1864}$ 


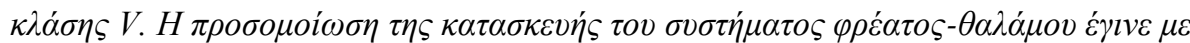

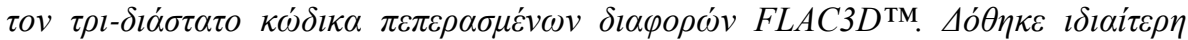

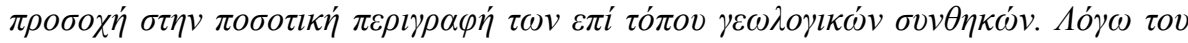

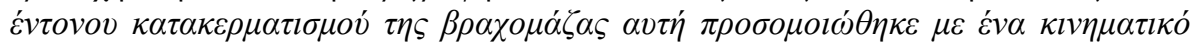

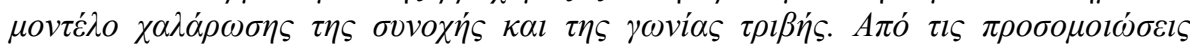

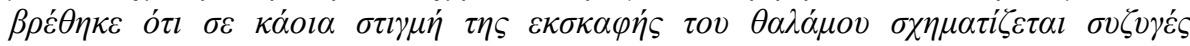

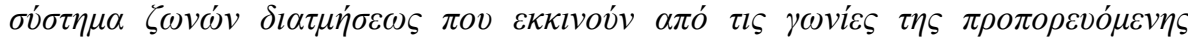

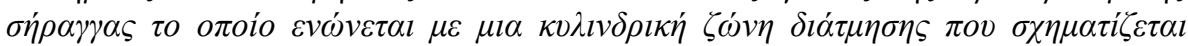

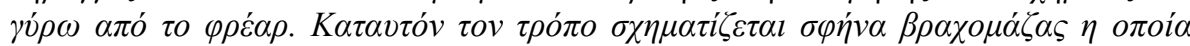

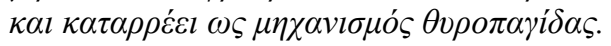

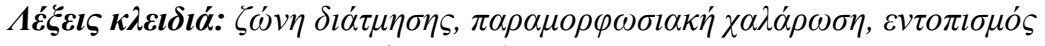

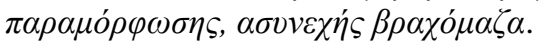

\section{Introduction}

This paper refers to the numerical simulation of the conditions that have lead to the collapse of the shaft-cavern collapse in Sao Paulo, Brazil (2007) constructed with the Conventional Tunnelling Method (CTM) or the New Austrian Tunneling Technique (NATM). These constructions (shaft and caverns) are close to the Pinheiros river, in the SW sector of the city, and are part of the new Line 4 (Yellow Line) of the presently expanding São Paulo Metro. This line is $12.5 \mathrm{~km}$ long, linking city center with western suburbs with four interchange stations. An artistic isometric view of the access shaft the two antidiametrical stations (caverns) and the associated running tunnels are shown in Figure 1a.

On the afternoon of Friday 12th January 2007, a dramatic metro construction accident occurred in São Paulo. Nearly the whole of one of the station caverns of $40 \mathrm{~m}$ length suddenly collapsed, immediately followed by collapse of nearly half of the adjacent $40 \mathrm{~m}$ diameter and $35 \mathrm{~m}$ deep station shaft. The multiple accident shown in Figure $1 \mathrm{~b}$ occurred so fast that there was no time for warning to be given. The seven unfortunate victims died after falling from the surface and becoming deeply buried under the collapsed rock and soil.

Referring to Figure 1a the design parameters of the Pinheiros Metro Station design were one shaft with a diameter of $40 \mathrm{~m}$, depth of $36 \mathrm{~m}$, two platforms of running length of $46 \mathrm{~m}$, height of $14.2 \mathrm{~m}$ and width of $18.6 \mathrm{~m}$, and two rail double track tunnels with a diameter of $9.6 \mathrm{~m}$. The height of overburden above cavern's crown is more or less $20 \mathrm{~m}$.

The shaft-tunnel construction is simulated by virtue of the 3D finite differences code FLAC3D ${ }^{\text {TM }}$ (Itasca, 2009). Special emphasis is given on the appropriate quantitative description of the geological conditions. This collapse incident is viewed in this work as a trap-door problem (Terzaghi, 1936) due to localization of strain along pre-existing joints of the rock mass above the cavern. The elastic and strength properties of the rock identified in lab are upscaled by using a special upscaling theory (Exadaktylos and Stavropoulou, 2008). A kinematic cohesion-friction softening Mohr-Coulomb model of the discontinuous rock mass is employed. This model is supported from fundamental rock mechanics considerations of heavily jointed rocks, namely the activation of pre-existing joints and subsequent sliding along their surfaces as the excavation advances and the rock adjacent to the openings is further loaded. From the simulations it was found that the failure is manifested with the evolution of shear bands starting from the corners of the top-heading of the cavern as this approaches the shaft, while retreating. Before this, another shear band initiates from the bottom of the shaft and also propagates upwards. The failure surface from the cavern extends upwards and forwards to connect with the shear band propagating from the shaft forming a rigid block of rock mass of weight of $20,000 \mathrm{t}$ that finally caves in the tunnel and shaft; hence, the system behaves as a trap-door mechanism.

$\underline{\text { XLVII, No } 3-1865}$ 


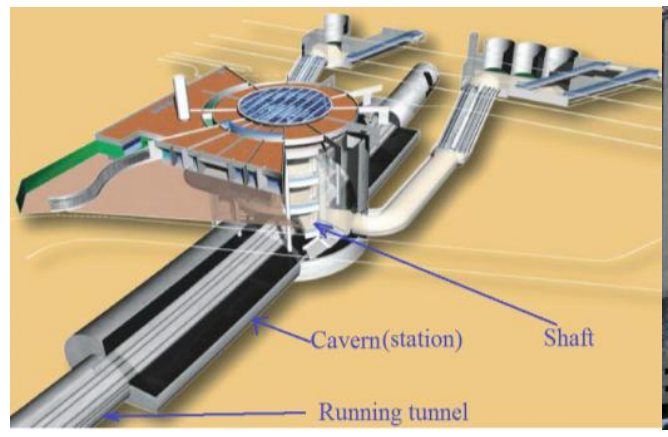

(a)

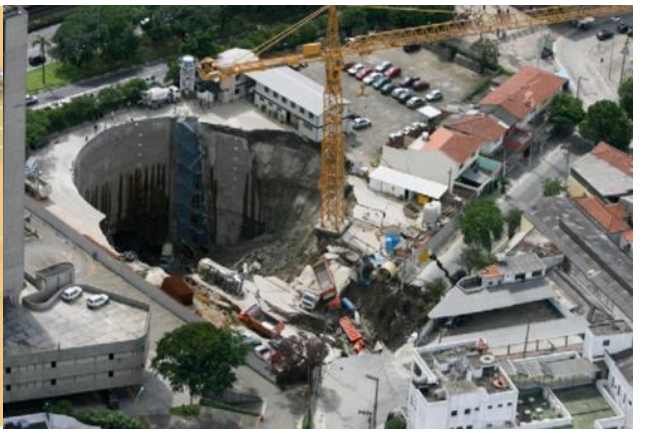

(b)

Figure 1 - (a) Artistic isometric view of the Pinheiros Station (after Barros et al. 2008), (b) collapse incident occurred on 12/Jan./2007, producing more than $20,000 \mathrm{t}$ of failed mtl.

During the bench excavation, very close of arriving to the shaft. The antidiametrical failure surfaces extending around the shaft as is indicated by the arrow may be observed.

\section{Rock Mass Structure}

The Pinheiros station where the incident has occured, is located in an area known as the Caucaia Shear Zone, resulting in a highly fractured medium (four main families of discontinuities, i.e. two subvertical and two dipping towards the tunnel walls as is illustrated in the lower hemisphere stereographic projection of Figure 2a. The main observed lithologies were biotitic gneiss and granitic gneiss of the Pre-Cambrian age. According to the Bieniawski classification, the following rock mass classes were observed: II,III,IV (partially corresponding to saprolite), and V (partially corresponding to residual soils). The appearance of the rock core from the borehole 8704 that was drilled near the centre of the station cavern is shown in Figure $2 \mathrm{~b}$. The eighteen plastic containers contain the (minimal) recovery of $18 \mathrm{~m}$ of overlying above the rock materials such as saprolite, soil and sand. The rock head, encountered first at the depth of $18 \mathrm{~m}$, that is at the elevation of $706 \mathrm{~m}$, was weathered gneiss. The near-vertical foliation is not appearing in the rock core.

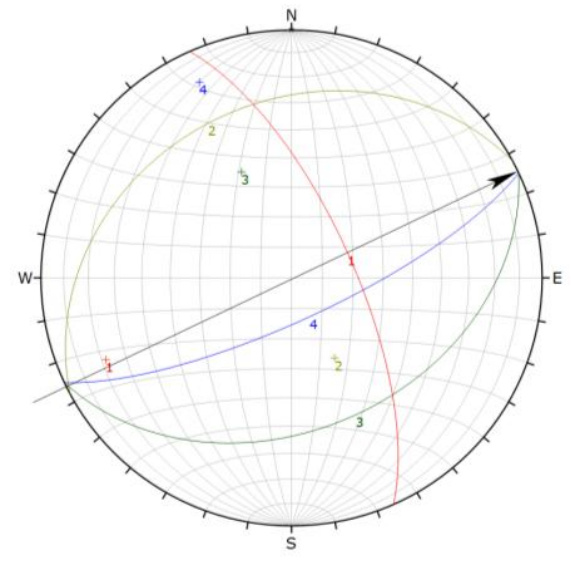

(a)

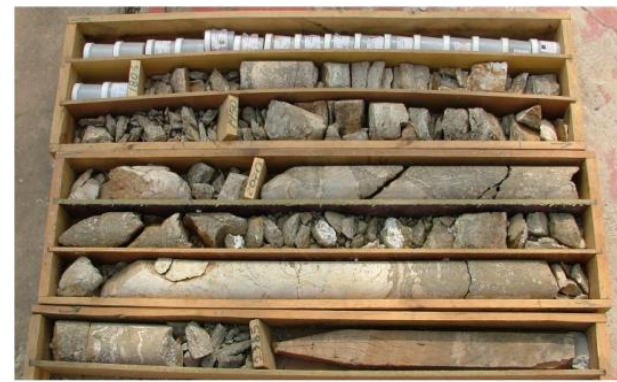

(b)

Figure 2 - (a) Stereographic projection of the four rock joint sets and the tunnel advance direction with the arrow (right), and (b) the appearance of the rock core from the borehole 8704 that was drilled near the centre of the station cavern. The eighteen plastic containers contain the (minimal) recovery of $18 \mathrm{~m}$ of overlying sand, soil and saprolite. The rock head, encountered first at $18 \mathrm{~m}$ depth, at elevation $706 \mathrm{~m}$, was weathered gneiss. The near-vertical foliation is not shown (Barton 2009). 


\section{Rock Mass Mechanical Behavior}

In this work the rock mass is assumed to be both isotropic and continuous. Both simplifying assumptions are reasonable due to the large number of joint sets transecting the gneiss and their dense network. Furthermore it is assumed that the rock mass behaves like a Mohr-Coulombic material with a linear elastic behavior up to the peak (p) strength, that is followed by a softening part and finally a residual (r) part as is illustrated in Figure 3a. Thus it is implicitly assumed that the discontinuous rock mass follows after it reaches its peak strength a kinematic cohesion-friction softening model as is illustrated in Figure $3 \mathrm{~b}$. For simplification it a constant and small value of the dilatancy angle of the rock mass is assumed. Further, the assumption of constant elasticity rock mass is justified by the fact that we do not expect damage (i.e. formation of new cracks) up to the peak load of the already heavily jointed rock mass.

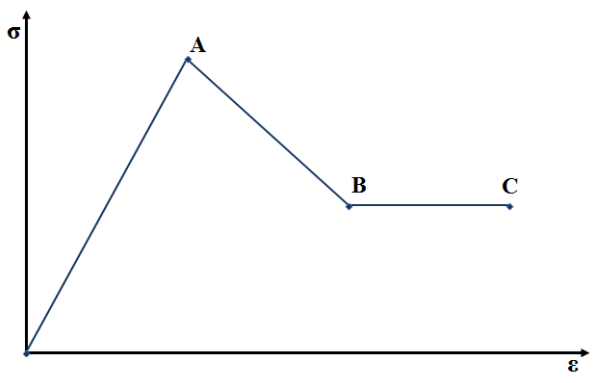

(a)

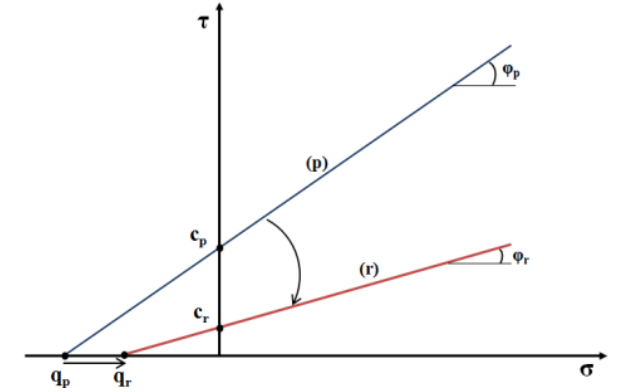

(b)

Figure 3 - (a) The continuous strain softening model illustrated by a simple stress-strain diagramm, and (b) the kinematic cohesion-friction softening model in the plane $(\sigma, \tau)$ for a heavily jointed rock.

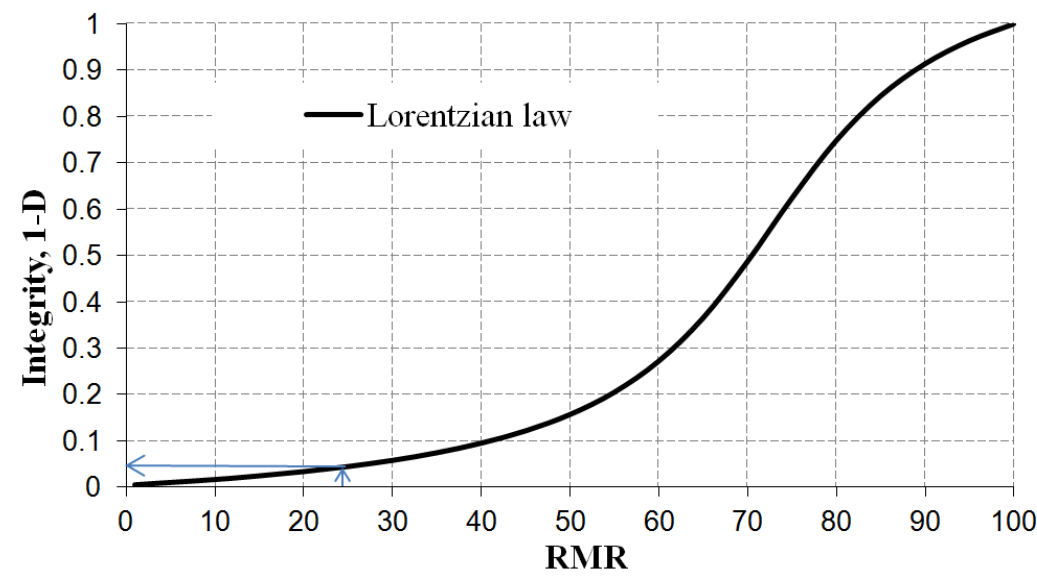

Figure 4 - Relation of rock mass integrity with RMR. Gneiss rock mass has properties that are found by multiplying the integrity of $5 \%$ with the intact rock parameters identified in the lab.

The elastic and strength properties of the intact rock identified in lab were upscaled by using a special upscaling theory suited for discontinuous rocks (Exadaktylos and Stavropoulou, 2008). From this paper we have taken the diagram shown in Figure 4. Based on a mean RMR of the order of 25 of the rock mass above the cavern it is found that the remaining integrity (1-D) - with D referring to damage of the rock ranging from 0 (completely disintegrated rock) to 1 (intact rock) is of the order of 0.05 or $5 \%$. Hence all the elastic (apart from Poisson's ratio) and strength parameters (apart from the friction and dilatancy angles) necessary for the model have been 
derived by multiplying the values of parameters found from lab tests by the constant factor of 0.03 (Table 1).

Table 1 - Mechanical parameters of the model of the rock mass and intact rock parameters.

\begin{tabular}{|l|c|c|}
\hline Rock Parameter [units] & Intact gneiss & Damaged gneiss \\
\hline Elastic modulus [GPa] & 100 & 5.1 \\
\hline Poisson's ratio & 0.16 & 0.16 \\
\hline Peak Cohesion [kPa] & 8000 & 400 \\
\hline Peak Internal friction angle [deg] & 34 & 34 \\
\hline Residual Cohesion [kPa] & - & 30 \\
\hline Residual Internal friction angle [deg] & 20 & 20 \\
\hline Dilatancy angle [deg] & 10 & 10 \\
\hline Tensile strength [MPa] & 12 & 0.6 \\
\hline
\end{tabular}

For this rock mass model one should prescribe the two decreasing curves of cohesion and friction angle with the accumulation of plastic shear strain in the rock mass and feed them as an input into the FLAC3D code like those shown in Figure 5. Hence, the plastic shear strain is chosen as the softening (aging) parameter of the rock adjacent to the shaft - cavern construction as it is loaded during excavation.

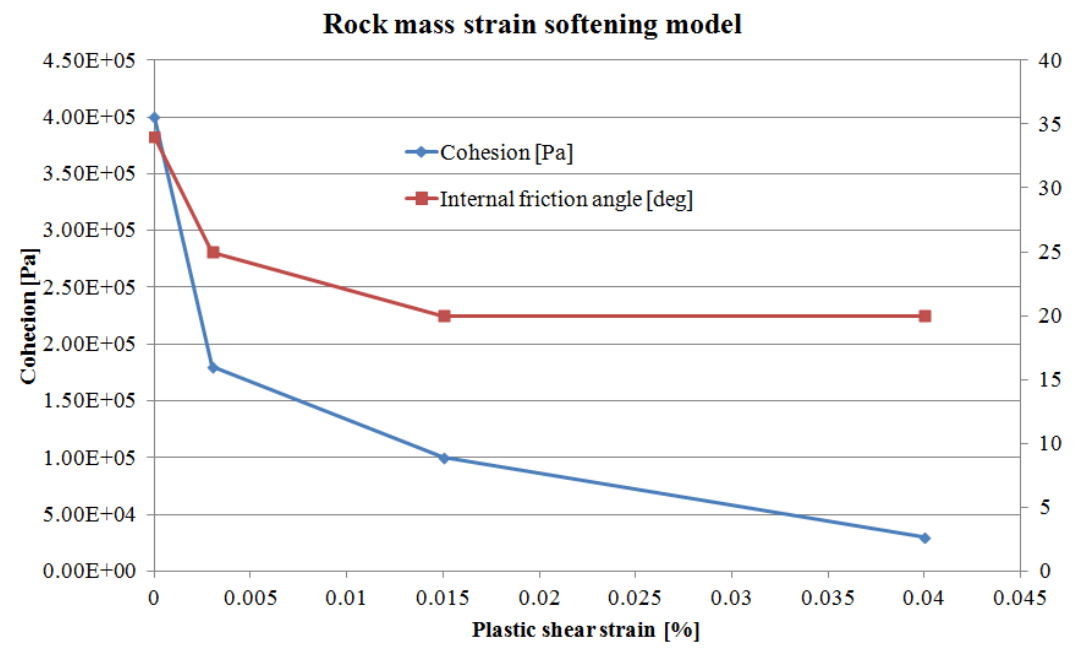

Figure 5 - Both $\mathrm{c}$ and $\varphi$ strain softening models.

\section{Numerical Simulations and Results}

The shaft-tunnel construction is simulated by virtue of the 3D finite differences code FLAC3D $\mathrm{D}^{\mathrm{TM}}$ as is shown in Figure 6. It should be noted that 3D modeling is indispensable in order to consider the interaction of both shaft and cavern constructions. Special attention was given to the appropriate creation of the nodes grid around the junction of the shaft with the cavern. Due to symmetry of the problem only one-quarter of the problem, i.e. the one quarter of the shaft and the cavern, have been simulated as is shown in Figure 6. The current model includes all station components such as the shaft and platform tunnel (cavern), apart from and running tunnel. The simulated excavation sequence follows that which have been applied in reality as is illustrated in 
Figure 6. The support (i.e. shotcrete lining, lattice girders, and forepoling) was not considered in this first attempt. The effect of the support to resist the loads applied to the rock was considered indirectly by slightly increasing the properties of the rock mass. This is justified by the fact that here we are only interested to investigate the rock mass failure mechanism around the shaft and the cavern. In a next publication we are going to consider the support and its installation sequence and its effect on ground deformations. The construction sequence was (i) excavation of the shaft down to the first working level (invert of the platform top headings); (ii) simultaneous excavation of the headings of the two platform tunnels in opposite directions; (iii) excavation of the bench (second working level), and then (iv) the excavation of the invert of the platform tunnels. During excavation of the platform tunnels, the top heading advanced in steps of $1.60 \mathrm{~m}$ from the shaft towards the running tunnel. The bench was excavated in advances of $2.0 \mathrm{~m}$ from the running tunnel towards the shaft. It is noted that the invert was not excavated due to the collapse at the end of the bench excavation. The model has been subjected only to gravitational loading and the lateral stress to vertical stress ratio is depicted by the known Poisson's ratio $v /(1-v)$. The low value of the ratio 0.18 (class of rocks with low Poisson's ratio between 0 and 1/6) means in turn a small dilatancy of the rock mass due to joint activation and formation. This assumption rests upon the fact that there not new formed fractures but simply frictional sliding along pre-existing joints with states more or less close to residual friction angle.

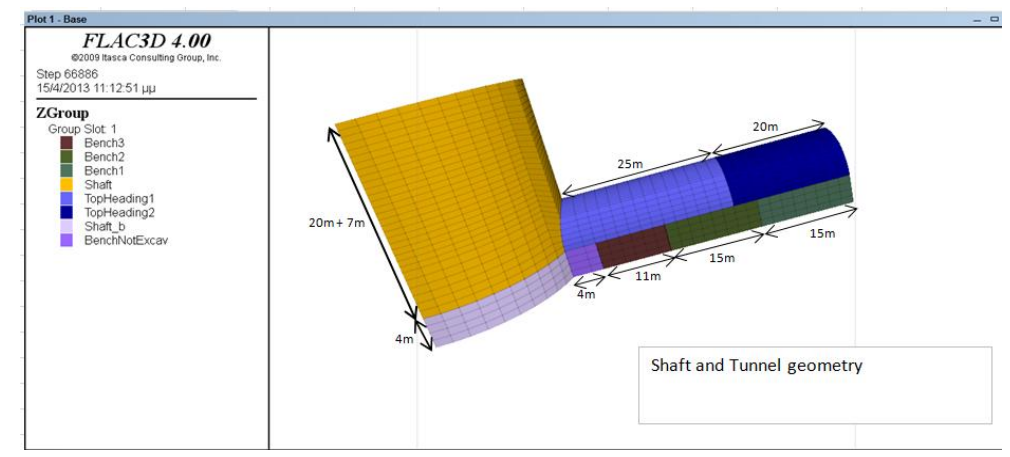

Figure 6 - Simulation of the cavern-tunnel construction steps by virtue of FLAC3D.

The localization of plastic shear strain along shear bands after the excavation of the third bench (only one bench remaining to reach the shaft) is clearly illustrated in Figure 7a. At the same more or less excavation step, that was actually just before the collapse, the formation of the symmetrical shear bands around the cavern are shown in Figure 7b. These shear bands, as was expected, have started from regions with high stress concentrations (top - heading and shaft corners). The displacement distribution after final excavation and the isosurface of vertical displacement greater than $0.15 \mathrm{~m}$ is shown in Figure $8 \mathrm{a}$ and $\mathrm{b}$, respectively. It is worth noticing that inside the rock mass a polyhedral block enclosed by this isosurface of $0.15 \mathrm{~m}$ vertical displacement is formed that could collapse as a rigid body.

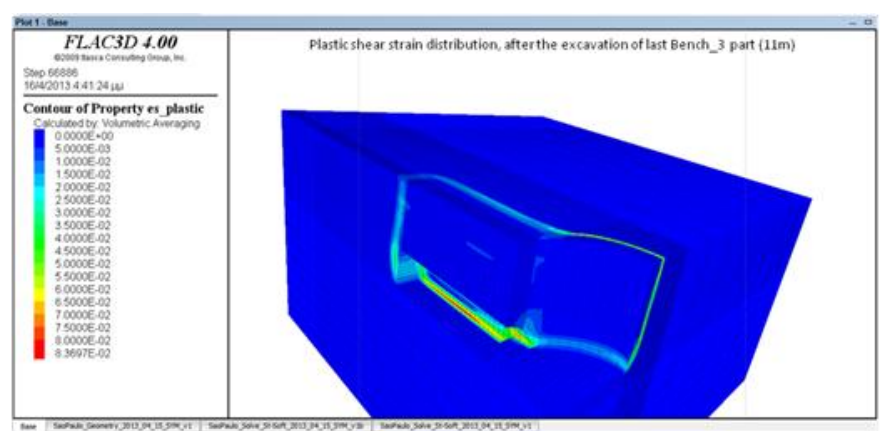

(a)

$\underline{\text { XLVII, No } 3-1869}$ 


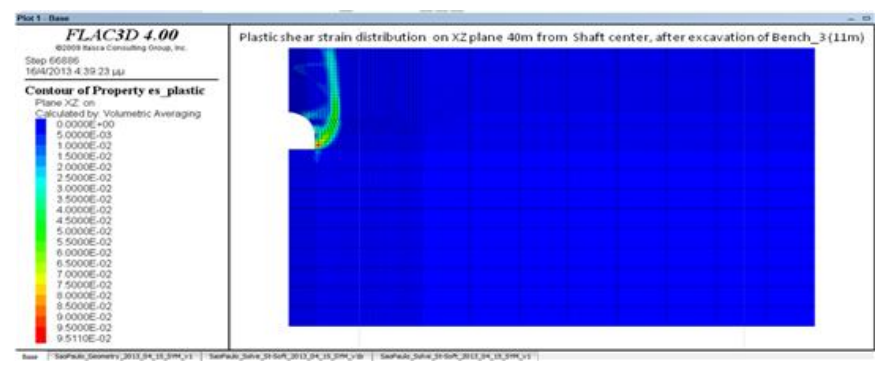

(b)

Figure 7 - (a) Final configuration of the shear band (localization of plastic shear) around the shaft and the cavern that finally collapses as a rigid body (one-quarter of the model). (b) Vertical section perpendicular to the cavern's longitudinal axis of the plastic showing the shear strain distribution.

One may also notice: (a) the similarity of the predicted trace of shear band around the shaft at the surface that is shown in Figure 7a with the actual failure at the collar of the shaft as is shown in Figure 1b; (b) the similarity of the predicted transversal to the cavern's axis vertical shear band at the far-end of the cavern at a distance of $45 \mathrm{~m}$ from the shaft's wall that may be seen in Figure $7 \mathrm{a}$, with the activated fault at the same location captured by the aerial photo of Figure $8 \mathrm{c}$; and finally, the time of collapse occurrence predicted by the model (i.e. just before the excavation of the last bench) which is in agreement with the actual timing of the collapse incident.

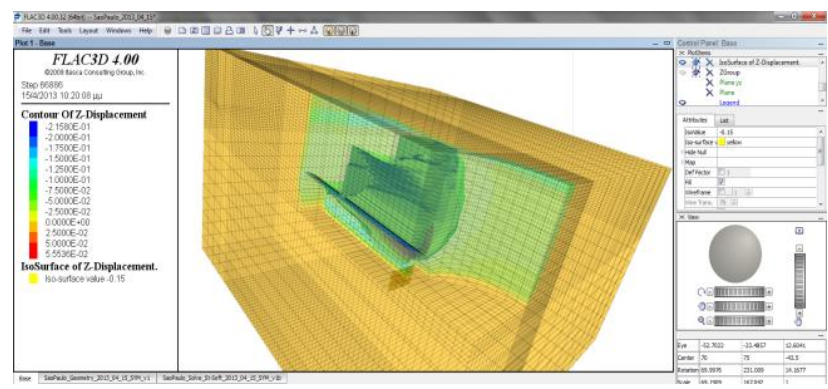

(a)

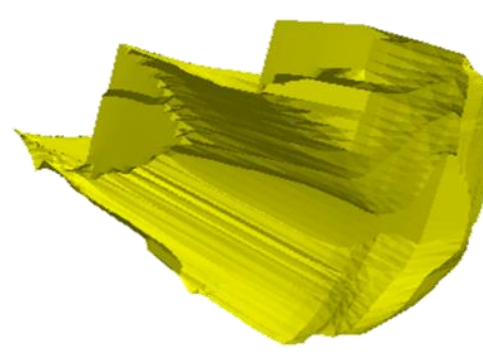

(b)

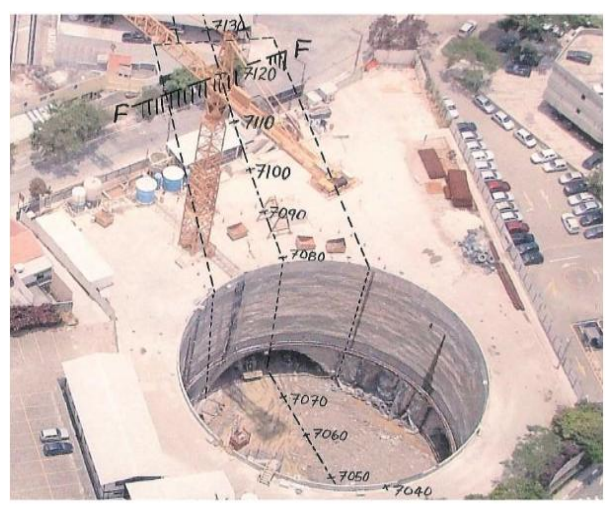

(c)

Figure 8 - (a) Displacement distribution after final excavation (b) IsoSurface of vertical displacement greater than $\mathbf{0 . 1 5}$ m (c) Aerial view of the Pinheiros Station shaft. The black curved arch at $20 \mathrm{~m}$ depth down the shaft wall is the topheading of the station platform cavern. The shaft wall chainage at $7080 \mathrm{~m}$ and the rear discontinuity (FF) at chainage 7120 $\mathrm{m}$, mark the approximate limits of the $\mathbf{4 0} \mathrm{m}$ long station cavern collapse (Barton, 2009). 
Finally, in Figure 9a we have plotted the vertical displacements predicted by the model from the onset until the collapse at the two history points TN-G2 and TN-G3 which are shown in Figure $9 b$.

History points: TN-G2 (blue line) hp id 31056 \& TN-G3 (green line) hp 31056

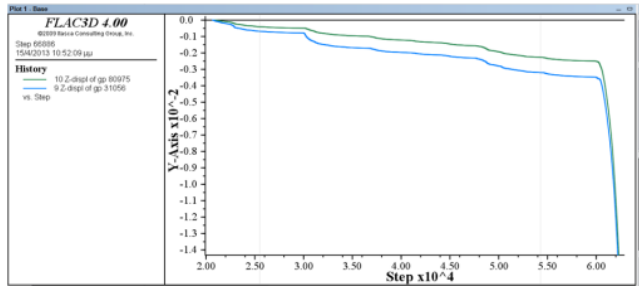

(b)

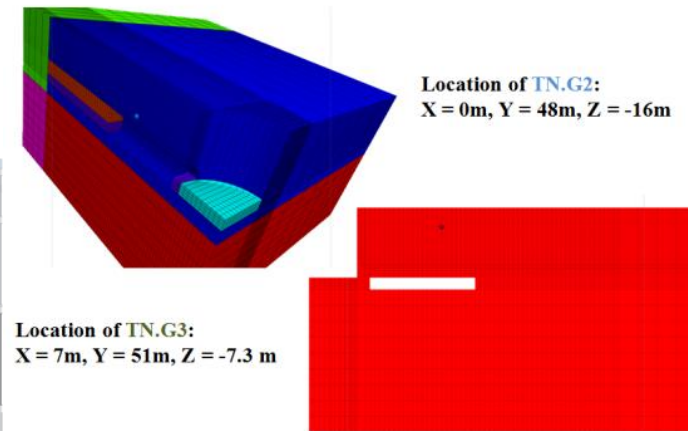

(c)

Figure 9 - (a) Vertical displacements during the excavation process measured on two history points above the tunnel (b) location of history points.

\section{Acknowledgments}

The authors would like to thank the financial support from the EC 7th Framework Project (FP7SEC-2010-1) DESURBS (Designing Safer Urban Spaces).

\section{References}

Barros J.M., Iyomasa W., Azevedo A.A., Eisenstein Z. and Assis A.P. 2008. Lessons from Brazil: pinheiros examined, Tunnels Tunnelling Int., 16-20.

Barton N. 2009. Differential weathering and adverse discontinuities were the apparent causes of a tragic metro accident in Brazil, Proceedings of the International Conference on Rock Joints and Jointed Rock Masses, Tucson, Arizona, USA, Special Paper.

Exadaktylos G. and Stavropoulou M. 2008. A Specific Upscaling Theory of Rock Mass Parameters Exhibiting Spatial Variability: Analytical relations and computational scheme, International Journal of Rock Mechanics and Mining Sciences, 45, 1102-1125.

Itasca Consulting Group, Inc. 2009. FLAC3D, Fast Lagrangian Analysis of Continua in 3 Dimensions, Ver. 4.0, User's Manual, Minneapolis: Itasca

Terzaghi K. 1936. Stress distribution in dry and saturated sand above a yielding trap-door, Proc. Int. Conf. Soil. Mech.., Cambridge, Mass., I, 307-311. 